\title{
The need for higher education in the sociology of traditional and non-conventional medicine in Italy: towards a person-centered medicine
}

\author{
Paolo Roberti di Sarsina • Mara Tognetti Bordogna
}

Received: 22 May 2011 / Accepted: 19 July 2011 /Published online: 12 August 2011

(C) European Association for Predictive, Preventive and Personalised Medicine 2011

\begin{abstract}
Italy is being forced to re-think her health plan as the national health service moves towards regional systems, individuals take more active responsibility for their health, the demand grows for traditional and non-conventional medicine and immigrants join the user list. Person-centered medicine and ever-wider skills attainable with the tools of analysis and research have made a new professional update indispensable. The proposed Master-Course on "Health systems, traditional and non-conventional medicine", first of its kind in Italy, fits this bill. The new forms of treatment that state and international bodies are prepared to recognize depend entirely on the universities training our professionals with concrete skills in planning, research and health management. Our paper performs an epistemological critique of the new health requirements and goes on to outline the reasons behind this training imperative.
\end{abstract}

Both authors contributed equally: P. Roberti di Sarsina, Coordinator and M. Tognetti Bordogna, Director of Master-course on "Health Systems, Traditional and Non Conventional Medicine", University of MilanoBicocca, Italy

\section{P. Roberti di Sarsina}

Expert for Non Conventional Medicine, High Council of Health, Ministry of Health,

Rome, Italy

P. Roberti di Sarsina $\cdot$ M. Tognetti Bordogna

Observatory and Methods for Health, Department of Sociology

and Social Research, University of Milano-Bicocca,

Milano, Italy

P. Roberti di Sarsina

Charity "Association for Person-Centered Medicine",

Bologna, Italy

P. Roberti di Sarsina $(\bowtie)$

Via Siepelunga, 36/12,

40141 Bologna, Italy

e-mail: paolo.robertidisarsina@unimib.it
Keywords National health system $\cdot$ Regional health systems $\cdot$ Traditional medicine $\cdot$ Non-conventional medicine $\cdot$ Person-centered medicine $\cdot$ Personalized medicine

The world's various health systems show two current trends: a steady alignment as to practice and procedure, with slow but constant regionalization and decentralization; and increasing resort to traditional and non-conventional medicine. These processes call for specific skills if they are to be effectively adjusted to, especially on the part of top management and decision-makers.

The need for constantly updated knowledge is due not just to changing organizational and operative patterns within health services, but to new chronic and crippling diseases and pandemics calling for specific know-how on the part of national health services and their welfare networks, plus knowledge of how world health systems work and the health and prevention measures currently being taken.

Another factor that challenges us to upgrade our understanding is that the end-user is often new, and used to different health systems (immigrants). Add to this that people are increasingly insisting on choose their treatment and style of health practice for themselves, beginning with traditional and non-conventional medicines [1-3].

Acquisition of this know-how is also a challenge to veterinary medicine and especially organic zootechnics. Controls on commercially-bred animals and foodstuffs of animal origin involve the public veterinary service and immediately affect consumer health as well as eco-sustainable animal raising in conditions that protect biodiversity.

We urgently need the tools to understand the changes afoot in society and its health systems and agricultural processes; and our knowledge must translate into healthcare 
answers and policy proposals consistent with and catering to the transformations around us.

Operators and decision-makers in the various echelons of welfare and health organizations (whether public, market-oriented or service-related) are being challenged to come up with the right answers and decisions within organized systems that are themselves continually evolving and targeted by an ever more holistic health demand. In a climate of democratic interchange they are being called on to plan, implement and manage social and health schemes in a new way geared to a more appropriate public health and welfare service at the centre of which is the whole human being.

\section{A social and ethical challenge}

A "dual liberty" thus needs to be recognized - the individual's and the doctor's right to choose the avenue of therapy, answering as this does to the spirit of article 32 of the Italian Constitution. Part of such recognition still awaits Parliament's approval of a national framework law on traditional and non-conventional medicine as well as the green light on the high-level training program such as the proposed Masters in "Health systems, traditional and non-conventional medicines" - the first of its kind to be adopted in Italy.

That traditional and non-conventional medicine has come to occupy a stable innovative position in public health is now fully established and accepted at home and abroad. This is proved first by the mounting recourse to non-conventional medicine (NCM) throughout Europe and the world (according to EURISPES, in Italy 11 million Italians, $18.5 \%$ of the population, choose $\mathrm{NCM}$ ), and second by the growing theoretical and practical interest being shown in the area by the university, hospital and general healthcare system across the European Union [4, 5].

The existence of the present Master's training program is itself concrete evidence that traditional and non-conventional medicines are gaining more mature status in Italy and that a spirit of pluralist dialogue is being felt in collective and individual health, the fruit of cultural emancipation, freedom to choose, a pro-health attitude and the urgent imperative of sustainability [6-10].

The ethical side

Although the Medicines listed by the FNOMCeO have gone through various stages of Parliament, there seems to have been little positive feedback in the medical world. This has meant that patients - often nursing prejudices of their own - have tended to find out about the range of treatments off their own bat, while under-informed GPs have been equally caught up in prejudice - some for and some against-without pondering the very real risks that such inbuilt prejudice entails.

The Supreme Court has ruled that only doctors have the professional qualifications to practice non-conventional medicines.

Against a 20-year backdrop of Parliament failing to ratify a score of variously proposed bills to regulate the position, in all this time it is only private training organizations that have conducted post-graduate medical training in Italy.

Although use of NCM has remained at the 'grass roots' level of patient initiative, the academic institutions would have ample opportunity, did they so wish, to promote new initiatives in the NCM field: for pre- and post-graduate training they could draw on the hundreds of qualified private training instructors to provide patients and health officials with reliable information, leading to more evidencebased therapy strategy and the generation of new knowledge, and meanwhile improving the results of medicare in terms of drug economics and a sustainable equilibrium.

We hear complaints in all quarters that funds are lacking to set in motion any proper organic integration strategy. Meanwhile patients of every social extraction and with all manner of pathologies are using NCM on a daily basis, despite the most fragmentary information as to how far NCM has penetrated the medical and academic world.

Law 3/2001 modified clause V of the Constitution and thereby launched federalism, since when healthcare has been profoundly regionalised in terms of planning and resource management. This has given the Regions a more central role vis-à-vis government and parliament [11, 12].

The changes to clause $\mathrm{V}$ involved redefining the duties of the Ministry and the Regions: we no longer have the Ministry regulating and the Regions adjusting accordingly, but principles laid down by the State, and Regional laws to implement them. In the years since the Constitution was changed the two levels have had difficult relations, mainly because the Ministry in daily practice has found it hard to adjust its role so that the Regions have constantly been obliged to assert their powers.

To avoid further regional fragmentation, we clearly need a national law confirming that all non-conventional medicines, without any form of demagogic discrimination, are fully recognised on an equal footing. This will properly extend the constitutional right to choose freely among, and have equal access to, NCM treatments.

The freedom to choose entails being fully informed as to the various possible diagnostic and therapy approaches, as well as having full access to the medicines used by the various branches of NCM.

Any such legislation must be based on precise definition of the criteria accreditation procedures for trainees, free from all 
conflict of interest, as well as the training curricula: rules need drawing up to govern professional practice and authorize non conventional medicinal products, remedies and prophylaxis.

The economic sustainability of integration becomes a problem in its own right, if one notes the discrepancy between essential levels of medicare guaranteed to all citizens - clearly defined as a basic point of healthcare uniformity-and essential levels of social assistance — still completely lacking.

Pending inclusion of NCM practices in the National Health System, it is hence indispensable we redefine the criteria for accessing essential levels of such assistance.

At present the whole idea of health as a right guaranteed to every human being seems in jeopardy. This is partly due to breakdown of the "social contract" drawn up between modern biomedicine and western society over a century ago: we will attend to social medicine and you can enjoy a monopoly in the health field. Now that biomedicine is faltering and unable to keep its side of the bargain, the other contractual party - the State and the society it representsseems minded to challenge the original contractual obligation.

The ups and downs of biomedicine in this era of crisis and uncertainty bring new opportunities for reflection and action to all who insist on viewing health as a key to understanding the new social landscape that is materializing at the dawn of the twenty-first century.

It is true that Cartesian reductionism has enabled medicine to make extraordinary progress; but in confining itself to this partial vision, medicine has tended largely or completely to fragment and objectify the classificatory processes, forgetting that human beings are made up of thoughts, emotions, beliefs, faiths, feelings, ideals, past experience and spirituality: forgetting, therefore, that a human existence does not unfold in a sequential manner.

Awareness of this enables us to analyse the changes afoot within the health organizations and networks [13-17].

The process of democratization which is deranging this order set in with the eighties and nineties; the first to be affected is the patient, who finds he no longer stands subordinate to the doctor but can share some of the power and responsibility.

Tardy though this revolution is compared to other walks of social development (politics or the economy, for example), it does highlight the subjective condition of patients, their values, forms of representation, preferred lifestyles and models of good health.

The figure of the expert is accordingly tending to change into one who holds some of the answers and should ideally stand by and advise as the patient chooses from among the options. For as the branches of knowledge ramify, so the specialists multiply; many or more than one of them will need consulting in any single case and a middle course steered among the differing information.
At this point biomedicine began to lose its ascendancy over the emerging non-conventional medicines, or rather anthropological systems of medicine; the doctor's word was challenged in the face of the various professions interacting to solve the health problem; his authority was shaken in the eyes of the patient who more and more began to seek second opinions, parallel practices and remedies.

As the wind of pluralist democracy has swept through the health system, there has also been a far from negligible redistribution of power between the sexes: not just among doctors, but in all the ranks of the health profession the traditional gender differences are changing and seem sometimes to have reversed.

And yet, for all the increased standing of citizen and patient, non-medical professions, civil associations and movements, the price of democracy and pluralism has been a certain fragility and risk attendant on the new edifice which should not be underestimated.

Safeguarding people's health, making treatment personal, human and sustainable, presupposes that the patient be central in choosing the therapy. Society has changed its perception of quality in medicine and is demanding that institutions humanize medicine: it must be both humanistic and scientifically-based, hence person-centered medicine [18, 19]. We prefer the term "person-centered medicine" to "personalised medicine" for epistemological and anthropological reasons. Person-centered medicine is both more specific and less reductive. It calls for wider medical knowledge and practice, not only of how to treat pathology but how to generate health (health genesis). It is a systemic approach, not mechanistic or reductive. It typically adopts a unitary view of sentient being and the world; it values how body and psyche interact, what spiritual integrity means in a whole person.

Diagnosing and treating each human being requires that we find an individual center of gravity taking the whole of the person into consideration, their intrinsic unity, physical and mental: the incessant interaction of these levels forms the spiritual core of the human being, a unicum to be interpreted before it can be cured.

Person-centered medicine conduces to individual psychophysical equilibrium which is the basis of any sustainable equilibrium in any society, present or future.

Person-centered medicine is an expansion of medical knowledge and practice, not just in therapeutic but in health-genesis terms towards a genuine sociology of health, owing to its inclusive, not exclusive, nature, its systemic effectiveness which is just the opposite of the reductive, materialist approach à la Descartes.

In 2007 to her great credit, the then Health Minister Senator Livia Turco first included NCM among the subjects for the Experts of the High Council of Health (back in the 
days of the $15^{\text {th }}$ Legislature, nominating Paolo Roberti di Sarsina). After a chapter of failures, Parliament tried again in the $16^{\text {th }}$ Legislature to regulate the position of NCM country-wide: the Commission for Health of the Senate appointed Senator Daniele Bosone to coordinate a unified Bill governing non conventional medicines as practised exclusively by doctors, dentists and vets.

Certain key points emerge from this argument. One is the gap between a classic "healthcare system" and a "prohealth system" of the kind needed to re-program public health in the teeth of worldwide economic crisis. The traditional health system does not cover the full implications of health: there are so many significant factors that must be embraced by a pro-health system. It is imperative that we integrate and liaise among the various approaches to medicine as an art; a synergy must be struck between biomedicine and anthropological or traditional and nonconventional medicines, if we are to achieve a sustainable equilibrium and contain the cost of drugs. Our lands are more and more peopled by migrants with complex needs and different health expertise.

The social environment affects psychological processes which reflect in turn on our biology in the well-known "social health gradient". It may not be possible to eliminate hierarchies altogether from modern society, but the consequences can be offset in their varying forms: after all, the "health gradient" is not just confined to the poorer countries or the socially indigent. One's position on the social ladder only becomes health-impairing if one is deprived of certain opportunities connected with needs that everyone's wellbeing depends on: a say in how one lives, a chance to participate socially, a chance to meet one's basic health needs - there being no true liberty without emancipation.

"Gender health" is a real issue, connected to which sex one belongs to. Above all society needs a humanized medicine, lower iatrogenic side effects, respect for people's right to choose their pathway to care.

We need more and more accurate information, given the paltry number of large-circulation biomedical journals containing clinical information of relevance to doctors. Together with a heightened ethical sense, we need to be able to count on the reliability of scientific publications (the giant health industry channelling most of our health resources may dangerously cramp the autonomy and even results of research). It is no longer enough to learn about the origins of pathology; traditional and non-conventional medicines share the commitment to broadcast knowledge of how to generate health, entailing studies on the sources of physical, psychological and spiritual health; they share the ethical and social mission to generate greater responsibility and social emancipation.
To produce evidence of NCM effectiveness, resources must obviously be channelled into quality research. It is contradictory that the academic and institutional establishment should demand proof that NCM works when, with rare exceptions, no state funding is made over for the purpose.

Science stands in need of new paradigms of pluralism. That challenge for the future extends beyond biomedicine: we need to review the evidence-based approach and apply it to traditional and non-conventional medicine. Not only are the public health authorities still reticent about traditional and non-conventional medicine, the whole health system needs to set in motion a virtuous process whose central aim should be global care of the individual patient - person-centered medicine - a caring diachronic approach to the psycho-patho-biological human being. Ethics demand that we preserve, protect, promote, study, hand on and apply the cultural heritage of medical and anthropological health expertise, be it western or eastern, respecting the original integrity of the traditional paradigms and patrimonies. The epistemological status of medicine calls for reformulation, and the key to hand is "personcentered medicine".

\section{Medical responsibility}

In Italy the legal position of NCM prescribes that the only professional figures empowered to practice are qualified doctors and dentists, and qualified vets for veterinary medicine, trained in the schools of biomedicine and then by specific rigorous training courses appointed by public and private institutions and accredited for that purpose.

To guarantee protection of citizen health the FNOMCeO both upholds the principle of freedom to treat and calls on doctors rigorously to observe the Professional Code, especially in informing patients fully and correctly and in getting their informed consent that they are not being routed away from treatment of proven effectiveness. NCM may only be practiced under the direct professional responsibility of the doctor without faculty of delegation; the doctor is also forbidden to engage the help of outsiders $[20,21]$.

This puts its finger on the key issue: it is doctors pure and simple who practice these forms of medicine; nor is it one non-conventional medicine but a series of non-conventional medicines which are often lumped together as "different" by ill-informed mainstream medicine.

Freedom of choice

Undoubtedly our present world is on the brink of an unusually complex and far-reaching change in the history 
of medicine and public health, extending to different yet interrelated facets of the system: the idea of health and disease, the importance of the individual's own perception of his health status; the concept of prevention and attention to lifestyle; awareness of forms of suffering and distress that lie outside organic disease as such; a new relationship between patient and doctor based on trust and collaboration, bringing out the person's inner resources so that he or she can face up to problems and make independent yet informed decisions as to behaviour or treatment in keeping with personal health and lifestyle limitations; recognition that the best professional service is a combination of cognitive expertise, relating and communications skills and personal qualities; the relationship between citizen and health services; the phasing out of directional models in favor of a participatory approach giving patients their due, respecting their needs and upholding their free responsibility to choose the right treatment and improve their quality of life.

Nowadays a member of the public in the care of traditional and non-conventional medicine is not just an informed patient, but a competent and aware subject taking his life in hand.

As the WHO puts it, it is necessary and ethical to protect, safeguard, promote, study, hand on and apply the human cultural heritage of medical and health knowledge, whether western or eastern, fully respecting the original traditions and their various practices and approaches.

On $8^{\text {th }}$ November 2008 during the World Congress on Traditional Medicine held in Beijing, the WHO issued the "Beijing Declaration on Traditional Medicine" urging amongst other things "the need for action and cooperation by the international community, governments, professionals and health workers to ensure traditional medicine is used correctly as a significant part of all people's health endowment, according to each country's capacity, priorities and legislation".

\section{The need for top level training}

The new and changing scene calls for training programs reckoning with a plurality of Italian national and regional health systems. One of the top qualifications is a Master-Course.

University master-courses programs are a career opportunity for neo-graduates and those already working but in search of further specialization, a chance (if properly pitched) to broaden professional skills and knowledge.

Organizations promoting and preserving human health, conducting research and healthcare planning and tending the chronic and terminally sick have a quality requirement to train people with transversal skills for employment in high-up and decision-making positions.
The organization managing and dispensing health services can no longer neglect the economic side; this takes its place beside clinical and scientific considerations, as does an understanding of the demographic and social scenario.

Health policies and healthcare management strategies are changing, mirroring changes in the tools and techniques of management and research at large. In defining the needs of healthcare, the starting point is an effective health plan reckoning with people's new demands and needs for treatment, including traditional and non-conventional medicines. The economic side to planning, resource distribution, deployment of human resources and definition of targets in terms of effectiveness, efficiency and quality are all indispensable aspects of rational management. The objective is to obtain the maximum utility from the resources employed, be they human, instrumental or technological, and to adapt to emerging new needs.

\section{Conclusions, outlook and action}

Traditional and non-conventional medicines are slowly gaining ground in Italy despite the opposition of mainstream medicare. With regionalisation of public health, the mingling of cultures each with its own medical tradition, and a general shift by an internet-proficient public towards greater freedom to choose a personal style of therapy, Italy finds itself in line with a worldwide trend encapsulated in the 2008 Beijing Declaration.

Amid the confusion that such health pluralism necessarily entails, the authors believe that "person-centered medicine" best sums up the spirit of this flexible new movement. We no longer treat pathology but collaborate with a person in a bid to generate health amid the pitfalls of our hectic, overtechnological, environmentally-destructive society and its diseased development model. As a corrective to this, personcentered medicine adopts a unitary and systemic approach; it accommodates the complexity of natural phenomena and human nature; it studies the relations of man to his environment, how body and psyche interact, what spiritual integrity means in a human being; and stresses active patient responsibility for keeping healthy and being healed.

But this revolution calls for a new generation of health workers, by which we mean doctors and nurses, but also planners and administrators, researchers and consultants, pharmaceutical companies and service providers. The urgent need of the moment is to pass from proselytising and campaigning to training the new cadres. It is in this light that the new Masters course kicking off this autumn 2011 under the auspices of University of MilanBicocca and Bologna's Charity Association for Person- 
Centered Medicine, comes as a most timely (and no doubt overdue) venture. The course outline that is given in the Appendix must thus be seen as an integral part of the present article, reflecting a pressing need to pass from words to deeds.

\section{Appendix}

Masters course on "Health Systems, Traditional and Non Conventional Medicine"

Organizing bodies: Observatory and Methods for Health, Department of Sociology and Social Research, University of Milan-Bicocca, Italy (Mara Tognetti Bordogna) and the Charity "Association for Person-Centered Medicine", Bologna, Italy (Paolo Roberti di Sarsina) (http://www. medicinacentratasullapersona.org and http://www.mastersistemisanitari-medicinenonconvenzionali.org) [22].

Length of program: 1,500 $\mathrm{h}$ of professional training activities, including lessons, seminars, guided study and free study. It is completed by project work and periods of work experience affording practice in the chosen career avenue skills.

Participants are expected to spend 400 h' work experience at a public, private or service sector facility which may be arranged by the student or by the Masters placement service. At this stage participants will be supervised in their project work by a company tutor or university tutor.

Starting date: November 2011

Place(s) of attendance: Milan

Enrolments: 30

\section{Course description}

Aims: To provide participants with the tools for grasping and analyzing the real state of the health system at present and projected into the future, bearing in mind the dynamics of change and the increasing resort to traditional and nonconventional medicines.

This first edition sets out to give a sound theoretical and practical basis for the health professional: it will include rudiments of management and economics, clinical practice, familiarization with various differing schools of medicine and applied relating skills.

How traditional and non-conventional medicines are being included in healthcare systems will be a particular focus.
Contents: The Masters program divides into two broad areas: Sociology/Sociology of Health, and Human/Veterinary Medicine and Traditional and Non-Conventional Medicines. It will address the subjects of health, person-centered medicine, traditional and non-conventional medicines, anthropological health systems. To this end it will survey various health models and their impact on welfare, and go into the latest topics of Health Sociology.

As part of planning and assessment of health systems (regionally, nationally, internationally) course participants will be taught to analyze, quantitatively and qualitatively, the inequalities of health arising from the various systems of treatment and research.

Suitable for: Doctors, dentists, vets, biologists, dispensing chemists; administrators, executives and managers; graduates in humanities and social sciences; Local Health Unit staff, workers in hospitals, especially those with wellness departments, the Scientific Health Institute, Foundations and Hospices, Palliative Care Centers; health workers at Local Authority social services, in the service sector, in private and/ or accredited facilities; regional officers and administrators; $\mathrm{PhD}$ and university researchers; researchers in private and public organizations; observatory staff; members of the public if in possession of the right qualifications. Those with a foreign study qualification may take part provided it is declared equivalent to one of the above qualifications by an Italian academic authority.

Professional outlets: Top health-system management positions with responsibility for organizing and running the various health facilities with their complex working units (in hospitals and/or throughout the surrounding areas). Coordination or consultation within public, private and service-sector institutions, as well as regional health offices, agencies and health units, at the health ministry, in clinics, pharmaceutical companies, service companies or hospital and hospice suppliers. Consultant firms, epidemiological observatories, research centers, wellness centers, research teams studying health systems and traditional and nonconventional medicines, and in general the university.

Applications: Interdisciplinary contributions to the study of health systems; theory and epistemology of health system models; health systems: models, competition, integration; sustainable health across the world; national Health Service and regional systems; services sector and health systems; welfare structures, biomedicine, traditional and nonconventional medicines; non-conventional medicines within health systems; inequalities in health; quali-quantitative healthcare methods; planning health systems; relating in therapy; bio-ethics. 


\section{References}

1. Tognetti Bordogna M. Concezioni profane di malattia: verso un nuovo paradigma della salute? In: Luison L, Minardi E, editors. Sociologia e sociologi nell'evoluzione delle politiche sociali. Milano: FrancoAngeli; 1989. p. 192-211 [in Italian].

2. Tognetti Bordogna M. Medicina ufficiale e medicina alternativa: due modalità comunicative. In: Pizzini F, editor. Asimmetrie comunicative. L'interazione medico-paziente. Milano: FrancoAngeli; 1990. p. 152-75 [in Italian].

3. Tognetti Bordogna M. I confini della salute. Paradigmi da contestualizzare. Milano: FrancoAngeli; 1989 [in Italian].

4. Roberti di Sarsina P. Le Medicine Non Convenzionali nel Programma d'Azione dell'Unione Europea in Materia di Salute: il Consorzio CAMbrella. La Medicina Biologica. 2010;2:29-37 [in Italian].

5. Menniti-Ippolito F, Bologna E, Gargiulo L, Forcella E, Sabbadini LL, Raschetti R. Caratteristiche individuali e familiari degli utilizzatori di terapie non convenzionali in Italia. Ann Ist Super Sanità. 2004;40(4):455-61 [in Italian].

6. Roberti di Sarsina P, Iseppato I. Non conventional medicine in Italy: the present situation. EuJIM. 2009;1(2):65-71.

7. Roberti di Sarsina P. Le Medicine Non Convenzionali in Italia. La Medicina Biologica. 2009;1:29-34.

8. Roberti di Sarsina P, Iseppato I. State of art of the regulative situation of non conventional medicines in Italy. J Altern Complement Med. 2010;16(2):141-2.

9. Roberti di Sarsina P, Iseppato I. Looking for a person-centred medicine: non conventional medicine in the conventional European and Italian setting. Evid Based Complement Alternat Med. 2009; doi:10.1093/ecam/nep048.

10. Roberti di Sarsina P, Iseppato I. CAM situation in Italy. Poster presentation. Inaugural scientific symposium: complementary and alternative medicine: evidence for integration. The Anlyan Center, Yale School of Medicine, New Haven. 2 April 2008.

11. Tognetti Bordogna M. L'evoluzione del sistema sanitario tra contenimento della spesa e modelli di funzionamento. In FNOM$\mathrm{CeO}$. Centenario dell'istituzione degli ordini dei medici. Roma: Health Comunication; 2010; pp. 151-174 [in Italian].

12. Tognetti Bordogna M. Les modèles de welfare sanitaires et les mèdecines non conventionnelles. Revue Sociologie Santè. 2010;32:263-92.

13. Cocconi $G$ et al. Attitudes to, and practice of, unconventional medicine by physicians in Italy. Eur J of Intern Med. 2006;17:32-7.

14. Albrecht GL, Fitzpatrick R, Scrinshaw SC. The handbook of social studies in health \& medicine. London: Sage; 2003.

15. Colombo E, Rebughini P. La medicina che cambia. Bologna: Il Mulino; 2003 [in Italian].

16. Freidson E. Profession of medicine. Chicago: University of Chicago; 1985.

17. Herzlich C, Adam P. Sociologia della malattia e della medicina. Milano: Franco Angeli; 2004 [in Italian].

18. Ingrosso M. La salute come costruzione sociale. Milano: Franco Angeli; 1994 [in Italian].

19. Roberti di Sarsina P, Iseppato I. Person-centred medicine: towards a definition. Forsch Komplementmed. 2010;17:277-8.

20. Roberti di Sarsina P. The social demand for a medicine focused on the person: the contribution of CAM to Healthcare and Healthgenesis. Evid Based Complement Alternat Med. 2007;4(S1):45-51.

21. Roberti di Sarsina P. 43 rd National Congress of the Italian Psychiatric Association. Consensus Conference: non conventional medicines. Evid Based Complement Alternat Med. 2005;2 (2):233-5.

22. Roberti di Sarsina P, Iseppato I. Why we need integrative medicine. EPMA J. 2011;2:5-7. 